\title{
STILBENOIDS FROM Vitis labrusca "ISABELLA" STEMS
}

\author{
M. A. Saputra, ${ }^{1}$ H. M. Sirat, ${ }^{1 *}$ and N. S. Aminah ${ }^{2}$
}

UDC 547.636.3

Studies on the chemical constituents of each part of the Vitis species, especially Vitis vinifera L., have been performed since this species has promising biological activities, including antioxidant [1,2] and anticancer activities [3, 4]. Meanwhile, investigations on the chemical composition of Vitis labrusca, to which the American grape belongs, have never been reported. This paper reports for the first time the chemical components of Vitis labrusca "Isabella".

The stems of V. labrusca "Isabella" were collected from Kebun Percobaan Banjarsari, Probolinggo, East Java, Indonesia in April 2008. The dried-powdered stems ( $3.0 \mathrm{~kg}$ ) were cold extracted using methanol at room temperature for 62 hours. The methanolic extract (342.14 g) was dissolved in methanol-water (9:1) and re-extracted successively with $n$-hexane (17.78 g) and ethyl acetate $(145.36 \mathrm{~g})$. The ethyl acetate extract was investigated.

A portion of the ethyl acetate extract $(135.36 \mathrm{~g})$ was fractionated by vacuum liquid chromatography using Merck silica gel 60 (230-400 mesh) with a solvent gradient of $n$-hexane-ethyl acetate to give 10 major fractions. Fractions 4 and 5 were further purified using several chromatographic techniques, including column chromatography on a glass column using Merck silica gel 60 (70-230 mesh), medium- pressure chromatography using Supelco Versa Pack Silica Cartridge $(40 \times 75 \mathrm{~mm})$, prep-TLC and centrifugal prep-TLC using Merck silica gel $\mathrm{PF}_{254}$, and also by Sephadex LH-20. TLC analysis was performed on Merck pre-coated silica gel $\mathrm{F}_{254}$ plates ( $2 \mathrm{~mm}$ thickness), and spots were visualized by UV light (254 and $365 \mathrm{~nm}$ ) and spraying with vanillin sulfuric acid reagent followed by heating. Melting points were measured using a melting point apparatus equipped with a Leica Gallen III microscope and were uncorrected.

Five compounds were isolated from the ethyl acetate extract. Based on the spectroscopic analysis and comparison with previously reported data, compounds $\mathbf{1 - 5}$ were identified as resveratrol (1) [5, 6], $\varepsilon$-viniferin (2) [7, 8], pallidol (3) [9], ampelopsin A (4) [8, 10], and $\alpha$-viniferin (5) [11].

The ${ }^{1} \mathrm{H}$ NMR (400 MHz) and ${ }^{13} \mathrm{C}$ NMR (100 MHz) spectra were recorded on a Bruker Avance 400 spectrometer using acetone- $\mathrm{d}_{6}$ as the solvent. Residual solvent was used as an internal standard. The IR spectra were run on PerkinElmer FT-IR spectrometer recorded in $\mathrm{KBr}$ pellet. The UV spectra were taken on a Perkin-Elmer UV-Vis spectrophotometer. Mass and LC-MS spectra were obtained from Kent Mass Spectrometry Services, United Kingdom and Department of Metrology, SIRIM BHD, respectively.
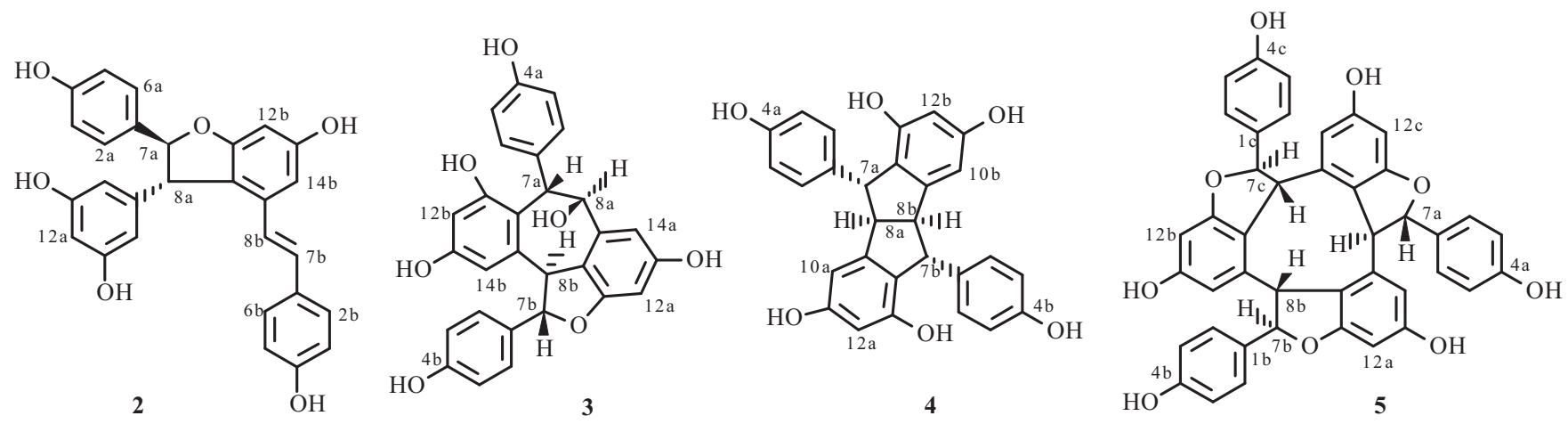

1) Department of Chemistry, Faculty of Science, Universiti Teknologi Malaysia, 81310, Skudai, Johor Bahru, Malaysia, e-mail: hasnah@kimia.fs.utm.my; 2) Department of Chemistry, Faculty of Science and Technology, Airlangga University, Kampus C, 60115, Surabaya, Indonesia. Published in Khimiya Prirodnykh Soedinenii, No. 5, September-October, 2013, pp. 793-794. Original article submitted May 16, 2012. 